\title{
Agronomic performance, chemical composition and Fusarium verticillioides resistance of Italian white maize varieties
}

\author{
C. Lanzanova*, A. Arrigoni, P. Valoti, M. Alfieri and S. Locatelli \\ Council for Agricultural Research and Economics (CREA), Research Centre for Cereal and Industrial Crops, via Stezzano 24, \\ 24126 Bergamo, Italy; chiara.lanzanova@crea.gov.it
}

Received: 21 September 2018 / Accepted: 23 July 2019

(c) 2019 Wageningen Academic Publishers

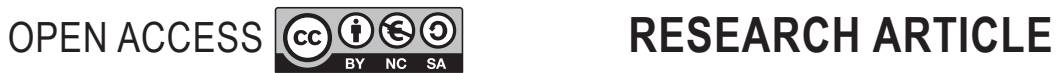

\begin{abstract}
White maize varieties were mainly grown in Italy before the advent of hybrids. The characterisation of their nutritional quality and safety will help to enhance the biodiversity of traditional materials, and to exploit it for food production. In fact, in recent years attention has been focused on the use of white maize varieties for the preparation of maizebased gluten-free products for coeliacs. Moreover it is also known that mycotoxin contamination of maize grain is a global threat to the safety of both human food and feed. In order to recover the biodiversity of traditionally maize, twenty-one Italian white maize varieties available at CREA Bergamo genebank were cultivated in Bergamo and Cremona in 2016. These genotypes were evaluated for grain chemical composition and agronomic performance; moreover an inoculation trial was carried out to test their resistance/susceptibility to Fusarium verticillioides. Chemical composition of the grain showed a wide range of variability; the samples from Bergamo accumulated more starch, whereas the plants grown in Cremona showed a higher content of proteins, lipids and total antioxidant capacity. Some varieties (VA86, VA1239 and VA1245) were valuable in both environments for their protein and lipid content, while VA185 showed a good 1000 kernels weight, in addition to interesting values of yield and test weight. Considerable variability was observed in fumonisin contamination. The response to fungal attack was very different in the two environments, the varieties grown in Cremona showed higher number of infected kernels at the inoculum point and higher level of fumonisins compared to the plants grown in Bergamo. Interestingly, some varieties (VA117, VA1213) showed a low fumonisin contamination in both locations. These genotypes could be potentially suitable for breeding programs with the aim to find new sources of genetic variability to improve the nutritional quality of maize genotypes and their resistance to pathogens.
\end{abstract}

Keywords: maize Italian germplasm, fungal pathogen, artificial inoculation, nutritional quality, mycotoxins

\section{Introduction}

Maize is a major crop worldwide, it is used for food, forage and for industrial purposes. This cereal is part of the staple diet of more than 200 million people in Latin America, Asia and Africa, and is used for the preparation of traditional foods (Rooney and Serna-Saldivar, 2003). The consumption of this crop for food increased in the last years also in developed countries, as ingredient for breakfast products, snacks, dietetic products and, in particular, for gluten-free foods, whose consumption is rising. From a nutritional point of view, maize is a good source of starch, proteins and lipids, but it also contains different bioactive compounds that are important for human health (Nuss and Tanumihardjo, 2010). The different types of maize are characterised by a grain colour varying from white to yellow, pink, red, blue or black. Most maize hybrids grown in the United States are yellow, whereas people in Africa, Central America and Southern United States traditionally prefer white maize. In some Italian regions (Veneto and Campania) food preferences favour white maize, as white polenta is considered a traditional dish. Italian traditional maize germplasm is one of the richest in Europe for number of populations and ecotypes (Brandolini and Brandolini, 2001). From the 1950s, the introduction of maize hybrid from the United States, able to give very high yields but 
characterised by a reduced genetic variability, has replaced the traditional varieties grown in Italy. These varieties were collected and stored in the largest germplasm bank in Italy, the collection of Council for Agricultural Research and Economics (CREA) in Bergamo, that contains more than 700 varieties deriving from different Italian regions. These genotypes represent not only a valuable source of potentially useful traits, such as resistance or tolerance to biotic and environmental stresses, but also an irreplaceable bank of highly co-adapted genotypes (Hartings et al., 2008). These varieties are regularly reproduced in the field and have been subject in recent years of studies on carotenoid content, soluble phenolic content, total antioxidant capacity and resistance to Fusarium attack (Berardo et al., 2009; Bitocchi et al., 2009; Lanzanova et al., 2016; Tafuri et al., 2014; Torri et al., 2015). Sub-groups of this large collection have been evaluated for traits related to the production of polenta, pasta and biscuits (Berardo et al., 2006; Zeppa et al., 2011). Maize (Zea mays L) is constantly attacked by fungal pathogens, and some of them can produce mycotoxins, which are potentially carcinogenic (Castegnaro and McGregor, 1998). As an example, fumonisins (FBs), secondary metabolites produced by the pathogen Fusarium verticillioides, accumulate during kernel filling and are also found in the end products with risks for animal and human health. The tolerance limits for the presence of FBs in corn, according to European directives, are 4,000 $\mu \mathrm{g} /$ $\mathrm{kg}$ for unprocessed maize intended for animal feed, and $1000 \mu \mathrm{g} / \mathrm{kg}$ for corn used for human consumption (EC, 2006, 2007). Monitoring the Italian maize productions for contamination by mycotoxins, including FBs, indicated that a significant proportion of the national production exceeds the tolerance limits set by current regulations (Berardo et al., 2011). Therefore, the development of plants able to withstand damage caused by fungal pathogens has been a significant challenge for maize breeders. Many breeders rely on natural infection to create sufficient levels of disease severity for the selection of resistant genotypes. However, there are few locations where natural infection is sufficiently uniform to make this selection efficient and successful (Mesterházy et al., 2012). Therefore, artificial infection is a suitable strategy for testing the plant's attitude towards mycotoxin resistance. Previous works indicated that kernel inoculation techniques used to infect ears, were effective in inducing $F$. verticilliodes attack and FBs accumulation (Balconi et al., 2014, Torri et al., 2015). In recent years the consumer's attention in relation to their diet is toward the consumption of wholesome food with excellent nutritional qualities and with a minimal risk for health. These traditional genotypes, despite having agronomic quality inferior to that of hybrids, can be used for prepare the maize-based food products aimed to entry into the market as a 'short chain'. The aim of the present work is to evaluate twenty-one traditional white maize varieties, maintained in the genebank collection of CREA Bergamo, for: (1) agronomic performance; (2) chemical composition of grain; and (3) resistance to F. verticillioides attack and FBs content by means of artificial inoculation field experiments.

\section{Materials and methods}

\section{Plant material}

Twenty-one white traditional maize Italian varieties, belonging to the genebank collection of CREA Bergamo, were used for this study (Figure 1). Varieties were chosen to create a panel representative of the Italian area; in fact their origin ranged from Northern Italy regions (Piemonte, Lombardia, Veneto, Emilia Romagna, Friuli), where the cultivation of corn is predominant, to the Southern Italy areas.

\section{Experimental design and samples}

\section{Agronomical trial}

The experiment was conducted during 2016, in Bergamo (249 m., 45⒍ ${ }^{\prime} \mathrm{N}, 9^{\circ} 64^{\prime} \mathrm{E}$ ) at CREA 'Azienda La Salvagna'. The plot size was $6.4 \times 3 \mathrm{~m}$, each plot consisted of 4 rows. The plot alleys, orthogonal to the maize rows, were $1 \mathrm{~m}$ wide. Investment of 17 plants/row $\left(4.5\right.$ plants $\left./ \mathrm{m}^{2}\right)$. In addition to the twenty-one white varieties, three maize hybrids with different class of maturity were sown: Dekalb DKC4316 (FAO maturity class 300); SIS Marano 501 (FAO 400); Maisadour Capsir (white FAO 300). In the agronomical trial the plant height $(\mathrm{cm})$ and ear insertion $(\mathrm{cm})$ parameters were measured. At harvest ears were collected by hand to quantify the grain yield q/ha (adjusted to a $15.5 \%$ moisture content). Ears for agronomic characterisation have been sib pollinated. Type, rank, ear length and ear diameter $(\mathrm{cm})$ were collected on five ears of each genotype. The moisture content and test weight $(\mathrm{kg} / \mathrm{hl})$ was determined by means of a Grain analyser computer (Dickey-John, model GAC 2100, Auburn IL, USA). All samples were dried at $40{ }^{\circ} \mathrm{C}$ for a week and 1000 kernels weight (g) was detected. Flotation index (FI) of maize kernels was calculated as described in Lozano-Alejo et al. (2007). Kernel were classified as: very hard, hard, intermediate, soft and very soft.

\section{Inoculation trial}

The experiment was conducted during 2016 in two environments: Bergamo (249 m., 45 68'N, 9 64'E) at CREA 'Azienda La Salvagna' and Casalbuttano (Cremona, 268 m., $45^{\circ} 14^{\prime} \mathrm{N}, 9^{\circ} 58^{\prime} \mathrm{E}$ ) at 'Cascina Graffignana'. Sowing was performed in the second half of May for both locations. The experimental unit was a four row plot, $6.4 \mathrm{~m}$ long, with rows spaced $0.75 \mathrm{~m}$ apart. All the plots received the same fertilisation ( $\left.\mathrm{kg} / \mathrm{ha}: \mathrm{N}=300, \mathrm{P}_{2} \mathrm{O}_{5}=100, \mathrm{~K}_{2} \mathrm{O}=100\right)$. Irrigation was carried out in order to prevent drought stress. Ears were left open-pollinated. Meteorological data (rainfall and mean temperatures) were registered in 

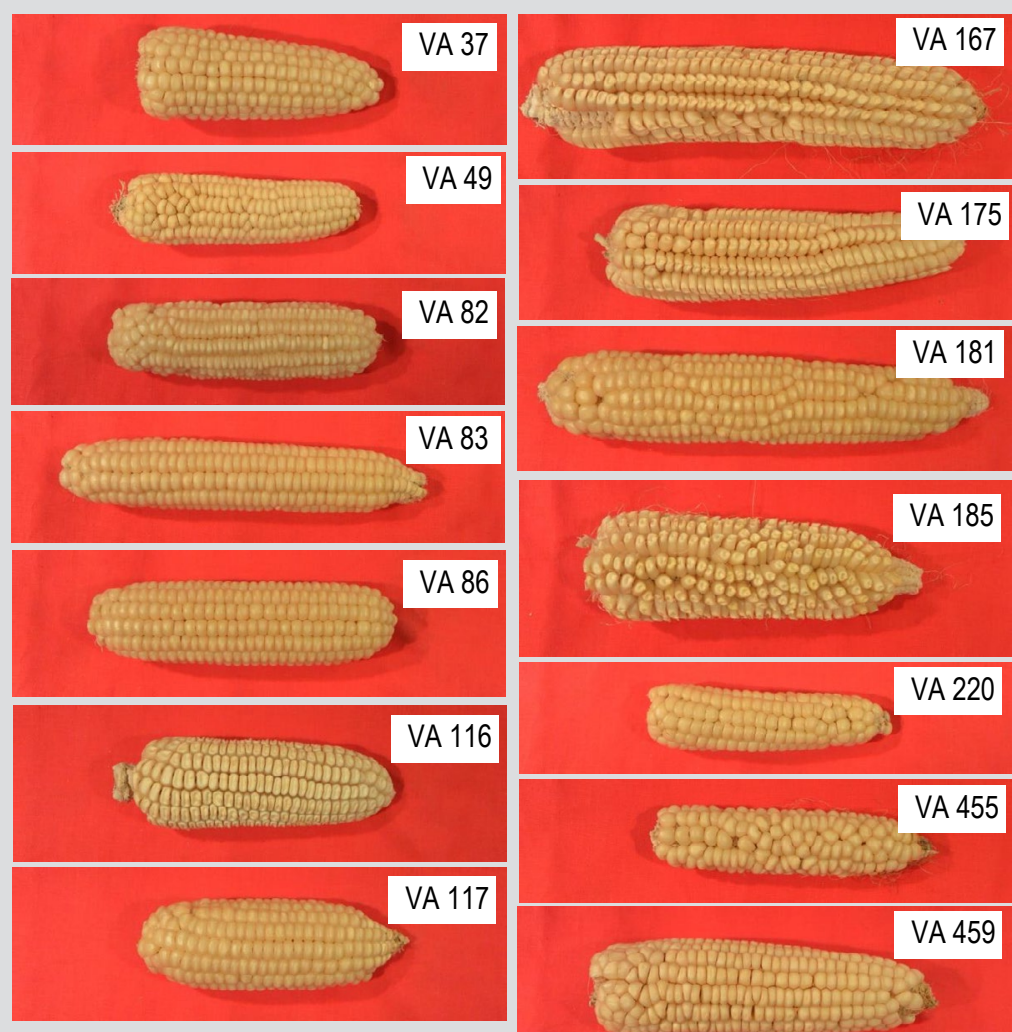

VA 185
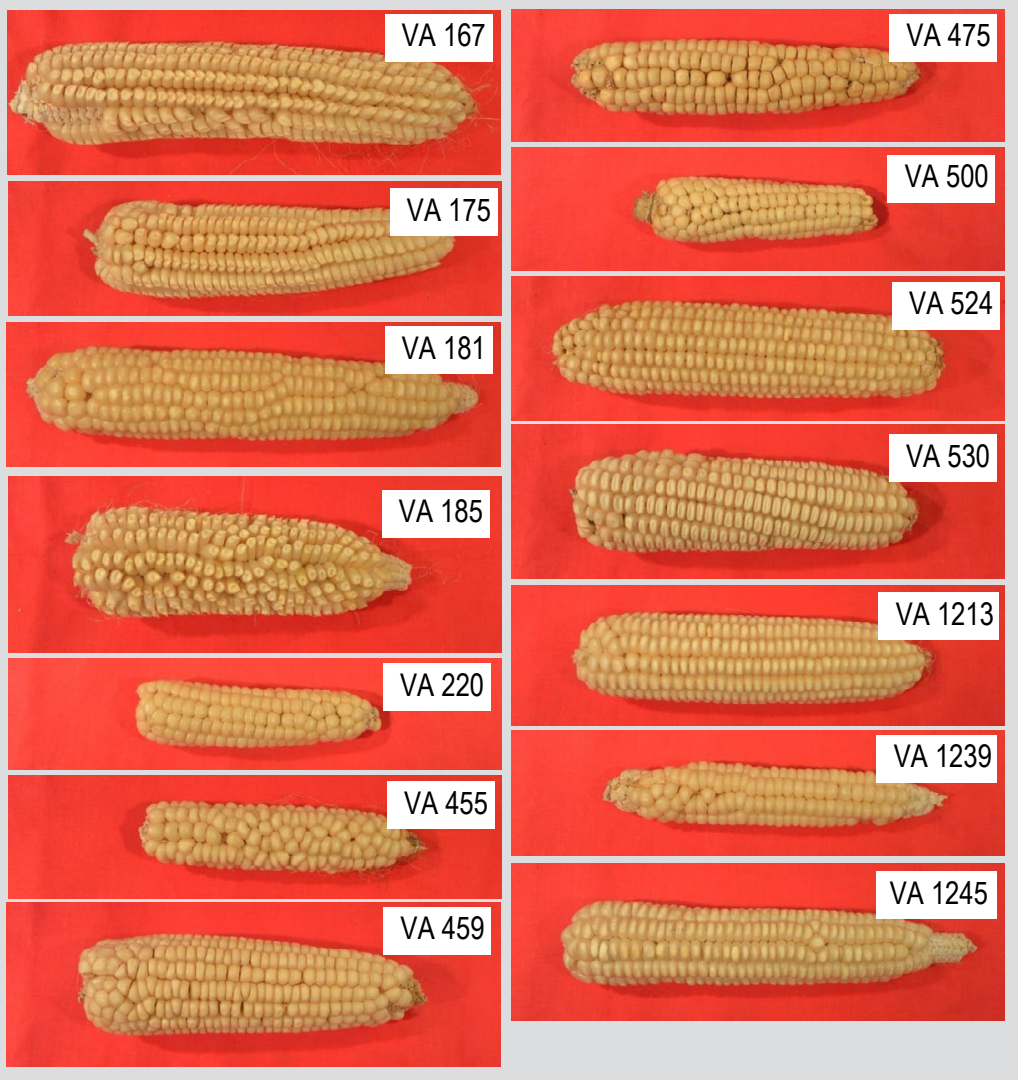

Figure 1. Photographic panel of 21 white maize varieties under study.

both location. At harvest ears were collected by hand and dried at $40{ }^{\circ} \mathrm{C}$ for a week. The ears of different inoculation treatments described below were shelled using an electric sheller, and kernels from each plot were mixed thoroughly in order to obtain a random distribution. Samples $(1.5 \mathrm{~kg})$ were taken and grains were milled with a ZM 200 Retsch Ultra-Centrifugal mill equipped with a DR 100 vibratory feeder (Retsch $\mathrm{GmbH}$, Haan, Germany) to a $1 \mathrm{~mm}$ sieve size and stored at $4{ }^{\circ} \mathrm{C}$.

\section{Inoculation method}

As described in Balconi et al. (2014) a kernel inoculation assay (KIA) was conducted in Bergamo and Cremona in order to evaluate the tolerance/susceptibility of varieties to $F$. verticilliodes pathogen. Three different treatments were tested:

- un-inoculated plants open pollinated (open), which represent environmental control;

- plants inoculated with sterile water, which represent an internal control of the inoculation method (water);

- plants inoculated with a water-spore suspension of a mix of two mycotoxigenic $F$. verticilloides \# 289 and 294 strains (Fusarium).
Ten primary ears of each variety were inoculated at 15 days after mid-silking, through KIA with fresh spore suspensions $\left(10^{6}\right.$ spores $\left./ \mathrm{ml}\right)$. At harvest the number of kernels having visible infection symptoms (rotting or mycelium growth) around the injection point was evaluated (number of seeds infected at the inoculum point; NIK).

\section{Fumonisins analysis}

Extraction procedure and fumonisins analysis were described by Berardo et al. (2011). Samples from Bergamo and Cremona were tested with the Ridascreen FBs ELISA test kit (R-Biopharm, Darmstadt, Germany), which detects total FBs (FB1, FB2 and FB3) at concentrations as low as $25 \mu \mathrm{g} / \mathrm{kg}$.

\section{Chemical analyses}

Samples were scanned in duplicate in the visible and NIR regions of the electromagnetic spectrum in reflectance (400-2,500 nm) at $2 \mathrm{~nm}$ intervals using a scanning monochromator NIRS 6500 (NIR Systems, Foss, Italy). Crude protein, crude lipid and starch (\% on a dry matter basis) were calculated using NIRS prediction equations by means of MATLAB program (MathWorks, Natick, MA, USA). Total antioxidant capacity (TAC) was expressed as 
mmol of Trolox equivalent (TE) for kg of dry matter and determined by specific calibration equation (Redaelli et al., 2016).

\section{Statistical analyses}

Principal component analysis (PCA) and Pearson correlation coefficient were carried out with PAST (Hammer et al., 2001).

\section{Results and discussion}

\section{Meteorological data}

Different climatic conditions were observed in the two locations. A most abundant rainfall was observed throughout the crop cycle in Bergamo compared to Cremona. The total rainfall from July to September was $418 \mathrm{~mm}$ in Bergamo and $101 \mathrm{~mm}$ in Cremona; a statistically significant difference in precipitation was observed (T-student, $\left.P<0.05^{*}\right)$. For the temperatures, the trend observed as growing degree days (GDDs) for both locations was similar for emergency (VE 46 GDDs) and flowering stages (VT tassel 732 GDDs). On the contrary, in Bergamo the ripening (R6 mature 1422 GDDs) was observed a week earlier compared to Cremona.

\section{Agronomic characterisation}

An agronomic trial was performed in Bergamo in order to characterise twenty-one Italian traditional white maize varieties. The name, origin and some agronomic and morphological data are reported for each variety in Table 1.

Among the selected materials there are also early varieties (VA37, VA49, VA220, VA475), 'Bianco Perla' (VA83, VA86, VA181), 'Rostrato' (VA167, VA175, VA185), and 'Ottofile' (VA1239) type. VA1245 (Ostenga del Canavese) is the only Italian white variety noted in the register of conservation varieties in Piemonte.

The seed texture was described through the Flotation index. The degree of vitrousness classified as very hard, hard, intermediate, soft and very soft (Lozano-Alejo et al.,

Table 1. Agronomic and morphological traits of twenty-one varieties and three hybrids grown in Bergamo during 2016.

\begin{tabular}{|c|c|c|c|c|c|c|c|c|}
\hline Variety & Name & Origin & $\begin{array}{l}\text { Flotation } \\
\text { index }\end{array}$ & $\begin{array}{l}1000 \text { kernels } \\
\text { weight }(\mathrm{g})\end{array}$ & $\begin{array}{l}\text { Moisture at } \\
\text { harvest (\%) }\end{array}$ & $\begin{array}{l}\text { Test weight } \\
\text { (kg/hl) }\end{array}$ & $\begin{array}{l}\text { Yield ( } q / \text { ha } \\
15.5 \% \text { moisture) }\end{array}$ & $\begin{array}{l}\text { Ear insertion/ } \\
\text { plant height (\%) }\end{array}$ \\
\hline VA 37 & Quarantino bianco & Brescia & hard & 257 & 17.4 & 75.0 & 34.0 & 36 \\
\hline VA 49 & Cinquantino bianco & Mantova & hard & 260 & 15.1 & 75.8 & 35.0 & 48 \\
\hline VA 82 & Bianco vitreo & Padova & very hard & 252 & 22.4 & 73.4 & 33.0 & 42 \\
\hline VA 83 & Bianco perla & Padova & very hard & 271 & 22.1 & 74.2 & 33.0 & 28 \\
\hline VA 86 & Bianco perla & Padova & very hard & 262 & 21.6 & 75.9 & 45.0 & 40 \\
\hline VA 116 & Wisconsin locale & Vicenza & intermediate & 262 & 15.8 & 70.9 & 54.0 & 42 \\
\hline VA 117 & Perla basso & Vicenza & intermediate & 351 & 17.0 & 76.5 & 40.0 & 31 \\
\hline VA 167 & Rostrato bianco & Gorizia & soft & 368 & 27.5 & 62.4 & 51.0 & 43 \\
\hline VA 175 & Rostrato $\times$ dentato & Udine & soft & 365 & 27.1 & 60.9 & 28.0 & 45 \\
\hline VA 181 & Bianco perla & Udine & very hard & 401 & 17.6 & 76.2 & 32.0 & 46 \\
\hline VA 185 & Rostrato tardivo & Udine & soft & 400 & 21.3 & 69.8 & 66.0 & 40 \\
\hline VA 220 & Cinquantino bianco & Modena & hard & 180 & 15.5 & 74.4 & 16.0 & 36 \\
\hline VA 455 & Nostrale bianco & Salerno & soft & 288 & 14.3 & 67.5 & 39.0 & 45 \\
\hline VA 459 & Nostrano bianco & Brindisi & soft & 196 & 18.6 & 66.4 & 28.0 & 50 \\
\hline VA 475 & Bianco precoce & Potenza & very soft & 280 & 16.0 & 69.4 & 20.0 & 39 \\
\hline VA 500 & Bianco avorio & Messina & very soft & 198 & 17.9 & 69.8 & 19.0 & 38 \\
\hline VA524 & Bianco cimalunga & Treviso & hard & 376 & 21.7 & 71.1 & 45.0 & 42 \\
\hline VA530 & Nostrano tardivo & Treviso & intermediate & 391 & 22.9 & 69.9 & 53.0 & 40 \\
\hline VA 1213 & Bianco di Stezzano & Bergamo & hard & 306 & 23.5 & 70.8 & 37.0 & 45 \\
\hline VA 1239 & Ottofile bianco dell'Albese & Cuneo & hard & 310 & 15.2 & 78.7 & 20.0 & 39 \\
\hline VA 1245 & Ostenga del Canavese & Torino & hard & 398 & 16.7 & 74.0 & 53.0 & 40 \\
\hline Mean & & & & 303.43 & 19.26 & 71.26 & 37.33 & 40.62 \\
\hline SD & & & & 71.01 & 4.04 & 4.50 & 13.29 & 5.20 \\
\hline \multicolumn{9}{|l|}{ Hybrids } \\
\hline CAPSIR & Maisadour & & hard & 330 & 18.5 & 81.2 & 104 & 45 \\
\hline DKC4316 & Dekalb & & intermediate & 353 & 14.1 & 78.1 & 105 & 34 \\
\hline Marano 501 & SIS & & hard & 253 & 18.2 & 82.2 & 111 & 39 \\
\hline
\end{tabular}


2007) is an important parameter to choose the end-uses of genotypes; in general for food preparation the hard maize kernels are preferred due to their greater yield and a higher quality meals and grits than soft maize (Guelpa et al., 2015). Most genotypes had vitreous texture; there were also some varieties with soft and very soft kernels such as VA167, VA175 and VA185 (Rostrato type), VA455, VA459, VA475 and VA500 which are typical of southern Italy.

Thousand kernel weight ranged from $180 \mathrm{~g}$ (VA220) to $401 \mathrm{~g}$ (VA181), with an average of $303.43 \mathrm{~g}$.

The moisture of the grain samples was measured at harvest. A great variability was observed for this trait: the minimum value was $14.3 \%$ for VA455, the maximum was $27.5 \%$ for VA167. In general the varieties coming from southern Italy showed lower humidity values compared to the Rostrato varieties.

Test weight $(\mathrm{kg} / \mathrm{hl})$ is an important parameter for rheological and commercial value of the product; in fact, in the food industry, grain with a high value of this parameter is appreciated. The varieties that achieved interesting values were 'Bianco Perla' type (VA83, VA86, VA181, VA117), VA1239 and early varieties (VA37, VA49, VA220). On the contrary Rostrato type varieties (VA167, VA175, VA185) and the varieties cultivated in the southern Italy (VA455, VA459, VA475, VA500) showed low values of test weight. This result is according to the negative statistically significant correlation between moisture and test weight $(\mathrm{r}=-0.56, P \leq 0.01)$.

As expected, the highest yield was reached by hybrids, which produced $107 \mathrm{q} / \mathrm{ha}$, in average. The varieties yield ranged from $16 \mathrm{q} / \mathrm{ha}$ (VA220) to $66 \mathrm{q} / \mathrm{ha}$ (VA185) with an average of $37.33 \mathrm{q} / \mathrm{ha}$. A positive and significant correlation was found between 1000 kernels weight and yield $(r=0.61$, $P \leq 0.01)$.

The genotypes that exceeded 50 q/ha were VA116, VA167, VA185, VA530, VA1245. As already pointed out in a previous study (Lanzanova et al., 2016) VA185 (Rostrato type), showed interesting agronomic characteristics such as 1000 kernels weight (400 g), test weight of $69.8 \mathrm{~kg} / \mathrm{hl}$ and grain yield of $66 \mathrm{q} / \mathrm{ha}$.

\section{Morphological characterisation}

Different previous studies were devoted to characterisation of Italian maize varieties (landraces) by means of morphophenological descriptors and molecular markers (Brandolini and Brandolini, 2001, 2009; Hartings et al., 2008). The focus of these studies was to explore the relationships existing among Italian traditional genotypes and classify the landraces in groups or races. In the present study sib pollinations were carried out, and plants and ears were evaluated using different morphological descriptors (CPVO, 2010). For the plant, the ratio (\%) between ear insertion and plant height was evaluated. According to the CPVO-TP/002/3 indications 18 genotypes fall into very small (>40\%)/small (40-45\%) categories; the remaining 3 genotypes fall in the medium class (46-50\%). This feature gives the plant a low centre of gravity, increasing its stability and resistance to lodging; therefore, the lower this ratio, the greater the plant stability. A positive and significant correlation was found between 1000 kernels weight and plant height $(\mathrm{r}=0.69, P \leq 0.01)$. In Figure 1 the great variability in the shape and size of the ear was shown. Twenty varieties showed a conical-cylindrical shape for the ear, while only VA37 showed a conical shape. Considering the thickness of the ears, $28 \%$ of genotypes showed a very short size ( $>15$ $\mathrm{cm}), 48 \%$ a short ear $(15-18 \mathrm{~cm})$, and $24 \%$ a middle-sized (19-21 cm) ear (data not shown). Considering the diameter of the ear (half-length), the most represented classes were thin (24\% 35-40 mm), medium (33\% 41-45 mm), big (24\% 46-50 mm). VA167 and VA185 (Rostrato type) showed larger diameter more than $50 \mathrm{~mm}$ (data not shown). The number of ranks varied from 8-9 for VA1239 and VA1245 to 19 for VA535. The most representative class (54\%) was medium with 14-16 ranks (data not shown).

\section{Chemical composition}

The content in nutritional and bioactive compounds of local genotypes was previously investigated. A high percentage of proteins and lipids was observed in a set of open-pollinated populations which were included in a core collection of European landraces (Berardo et al., 2009). Moreover, an analysis of antioxidant compounds in five pigmented genotypes included in the regional register of biodiversity of Marche was carried out (Bacchetti et al., 2013). Italian populations were screened for the carotenoid content (Berardo et al., 2009), soluble phenolic content (Tafuri et al., 2014), total antioxidant capacity (Redaelli et al., 2016). Some of Italian white varieties were analysed in a preliminary study by Lanzanova and co-workers (2016) for their agronomic and chemical parameters, in addition to quantification of FBs content. In the present study, open treatment from both locations were characterised for their grain composition: protein, lipid, starch content and TAC were shown in Table 2.

In average, varieties cultivated in Bergamo showed an higher starch content compared to those of Cremona with a slight increase of $2.64 \%$, which significance at T-Student test $\left(P=0.0004^{* *}\right)$. In both locations VA181, VA116, VA175, VA524, VA530 have accumulated an interesting starch percentage. VA185, with good agronomic qualities, presented starch content above the mean in both locations. VA1239 showed a low starch content in both locations, but reached the maximum protein content, together with VA49 and VA1245. The average protein content in Bergamo 
Table 2. Results of chemical evaluation of grain of twenty-one varieties grown in Bergamo and Cremona during 2016.

\begin{tabular}{|c|c|c|c|c|c|c|c|c|}
\hline \multirow[t]{2}{*}{ Variety } & \multicolumn{4}{|c|}{ Bergamo } & \multicolumn{4}{|c|}{ Cremona } \\
\hline & $\begin{array}{l}\text { Starch } \\
(\% \mathrm{dm})\end{array}$ & $\begin{array}{l}\text { Protein } \\
\text { (\%dm) }\end{array}$ & $\begin{array}{l}\text { Lipid } \\
\text { (\%dm) }\end{array}$ & $\begin{array}{l}\text { TAC }^{1} \\
\text { (mmol TE/kg dm) }\end{array}$ & $\begin{array}{l}\text { Starch } \\
(\% \mathrm{dm})\end{array}$ & $\begin{array}{l}\text { Protein } \\
(\% \mathrm{dm})\end{array}$ & $\begin{array}{l}\text { Lipid } \\
\text { (\%dm) }\end{array}$ & $\begin{array}{l}\text { TAC } \\
\text { (mmol TE/kg dm) }\end{array}$ \\
\hline VA 37 & 61.81 & 13.69 & 4.44 & 12.39 & 59.40 & 14.40 & 4.36 & 14.17 \\
\hline VA 49 & 60.32 & 14.53 & 4.25 & 13.56 & 59.32 & 14.62 & 4.54 & 15.16 \\
\hline VA 82 & 61.83 & 13.65 & 4.62 & 12.64 & 60.78 & 14.77 & 4.42 & 13.27 \\
\hline VA 83 & 63.05 & 13.33 & 5.11 & 12.90 & 60.63 & 14.27 & 4.81 & 13.51 \\
\hline VA 86 & 62.08 & 13.84 & 5.86 & 11.94 & 59.83 & 14.96 & 5.20 & 11.82 \\
\hline VA 116 & 63.55 & 12.55 & 4.39 & 14.15 & 62.32 & 12.95 & 4.31 & 16.16 \\
\hline VA 117 & 63.63 & 12.80 & 4.97 & 12.95 & 60.76 & 14.56 & 5.17 & 13.25 \\
\hline VA 167 & 61.62 & 13.55 & 4.68 & 14.03 & 60.87 & 13.91 & 5.02 & 13.75 \\
\hline VA 175 & 63.73 & 11.91 & 4.27 & 13.22 & 61.53 & 12.87 & 4.46 & 14.73 \\
\hline VA 181 & 64.46 & 12.40 & 4.85 & 13.38 & 61.78 & 13.03 & 4.51 & 14.33 \\
\hline VA 185 & 62.65 & 12.88 & 4.58 & 13.52 & 61.43 & 13.13 & 4.65 & 13.28 \\
\hline VA 220 & 60.99 & 13.93 & 4.79 & 13.40 & 58.35 & 15.25 & 4.97 & 13.37 \\
\hline VA 455 & 62.43 & 12.14 & 3.69 & 15.75 & 62.20 & 12.41 & 4.06 & 16.04 \\
\hline VA 459 & 62.56 & 13.03 & 3.28 & 15.05 & 61.38 & 12.98 & 3.32 & 15.26 \\
\hline VA 475 & 60.19 & 13.43 & 4.03 & 15.44 & 61.38 & 13.60 & 4.42 & 14.29 \\
\hline VA 500 & 62.28 & 13.46 & 4.28 & 14.44 & 59.87 & 14.20 & 4.19 & 14.58 \\
\hline VA 524 & 63.89 & 12.08 & 4.69 & 13.15 & 61.06 & 13.82 & 4.80 & 13.78 \\
\hline VA 530 & 63.76 & 11.76 & 4.54 & 13.92 & 61.33 & 13.42 & 4.32 & 13.08 \\
\hline VA 1213 & 63.16 & 12.39 & 4.24 & 13.59 & 60.56 & 13.41 & 4.61 & 14.06 \\
\hline VA 1239 & 58.02 & 15.91 & 4.77 & 12.22 & 58.76 & 15.64 & 4.81 & 12.91 \\
\hline VA 1245 & 60.84 & 14.28 & 4.67 & 13.22 & 59.75 & 14.76 & 4.73 & 12.95 \\
\hline Mean & 62.23 & 13.22 & 4.52 & 13.56 & 60.63 & 13.95 & 4.56 & 13.99 \\
\hline SD & 1.54 & 1.00 & 0.52 & 1.00 & 1.09 & 0.89 & 0.42 & 1.08 \\
\hline Min & 58.02 & 11.76 & 3.28 & 11.94 & 58.35 & 12.41 & 3.32 & 11.82 \\
\hline Max & 64.46 & 15.91 & 5.86 & 15.75 & 62.32 & 15.64 & 5.20 & 16.16 \\
\hline
\end{tabular}

showed a decrease of $5.3 \%$ compared to Cremona, with significance at T-student test $(P=0.016 *)$. The range of variation was rather large in both locations: from $11.76 \%$ dm (VA524) to 15.91\% dm (VA1239) in Bergamo and from $12.41 \% \mathrm{dm}$ (VA455) to $15.64 \% \mathrm{dm}$ (VA1239) in Cremona. As expected, a negative and significant correlation was found between starch and protein content $(\mathrm{r}=0.90, P \leq 0.01)$.

Considering lipid content the varieties did not show significant differences in the two locations. Lipid value of VA86 (Bianco Perla) was the highest observed in both environments while VA459 showed the lowest lipid content.

Many compounds generally present in maize grain contribute to its antioxidant properties: carotenoids, polyphenols, flavonoids and anthocyanins (Brewer et al., 2011). The global activity of all the antioxidant substances present in a raw material can also be expressed as total antioxidant capacity (TAC) (Serpen et al., 2007). Carotenoids are absent in white genotypes (Berardo et al., 2004), even if the content of antioxidant compounds such as soluble phenols, is not lower than in other genotypes (Tafuri et al., 2014). TAC analysis in the present work revealed a wide variation for this trait, which ranged from 11.94 (VA86) to 15.75 (VA455) $\mathrm{mmol} \mathrm{TE} / \mathrm{kg} \mathrm{dm}$ in Bergamo and from 11.82 (VA86) to 16.16 (VA116) $\mathrm{mmol} \mathrm{TE} / \mathrm{kg}$ $\mathrm{dm}$ in Cremona. TAC values observed for the Southern Italy varieties, are above the mean in both locations; on the contrary, varieties belonging to Rostrato type were characterised by lower TAC value. A negative correlation was found between lipid and TAC content $(\mathrm{r}=0.78, P \leq 0.01)$.

White varieties, although lacking in carotenoids, showed TAC values very similar to yellow-grain genotypes (Lanzanova et al., 2016). Previous data obtained on 162 yellow and pigmented maize varieties showed average 
values of $16.30 \mathrm{mmol} \mathrm{TE} / \mathrm{kg}$ dm with a range of 11.39 $32.27 \mathrm{mmol} \mathrm{TE} / \mathrm{kg} \mathrm{dm}$ (Redaelli et al., 2016). Besides their activity in the cell metabolism, antioxidant molecules are considered to play a role in the protection of the plant from fungi (Pereira et al., 2011); however, in the present study no significant correlation was found between TAC and mycotoxin content (data not shown).

PCA of varieties grown in Bergamo and Cremona was carried out on chemical parameters. Three principal components explained $98.5 \%$ of total variance. PC1, which explained $57.9 \%$ of the variance, was mainly related to protein content. PC2 accounted for $33.1 \%$ of total variance, which was attributed to lipid, starch and TAC. An additional $7.5 \%$ was contributed by PC3. It is possible to highlight the presence of varieties with valuable quality traits in both location: VA86 for lipid, VA1239 and VA1245 for protein content. VA185 shown a good starch content in both locations. The capacity to accumulate a large percentage of nutritional compounds in different environments, in spite of the diverse climatic conditions and agronomic performances, suggests that these materials could be considered as suitable raw materials for the food market.

\section{Responses to Fusarium verticillioides infection and fumonisin accumulation}

In Italian areal, Fusarium spp. are the most frequently and endemic occurring fungi and FBs are the main mycotoxins detected in maize grain (Camardo Leggieri et al., 2015; Pietri et al., 2012). The occurrence of these metabolites is dependent on different climatic conditions that are suitable to fungal infection and growth. Temperature, drought stress, insect damage, and other fungal diseases are the most influential risk factors with regard to maize Fusarium ear rot and FB accumulation (Cao et al., 2014; Miller, 2001). Meteorological trends observed during each growing seasons may play a fundamental role on these factors, as uncontrollable variable, so the use of resistant genotypes could be a good strategy to contrast the propagation of $F$. verticillioides in the Italian areal.

In this study a KIA was performed with spore suspensions obtained from a mix of two toxigenic F. verticillioides strains. This method is a good technique for an effective infection with consequent FB accumulation, and represents a suitable tool to select resistant/susceptible genotypes (Balconi et al., 2014; Miedaner et al., 2010; Reid et al., 1996). As internal control, ears inoculated with sterile water, allow the evaluation of environmental fungal infection through ear injury, because fungal spores can use wounds

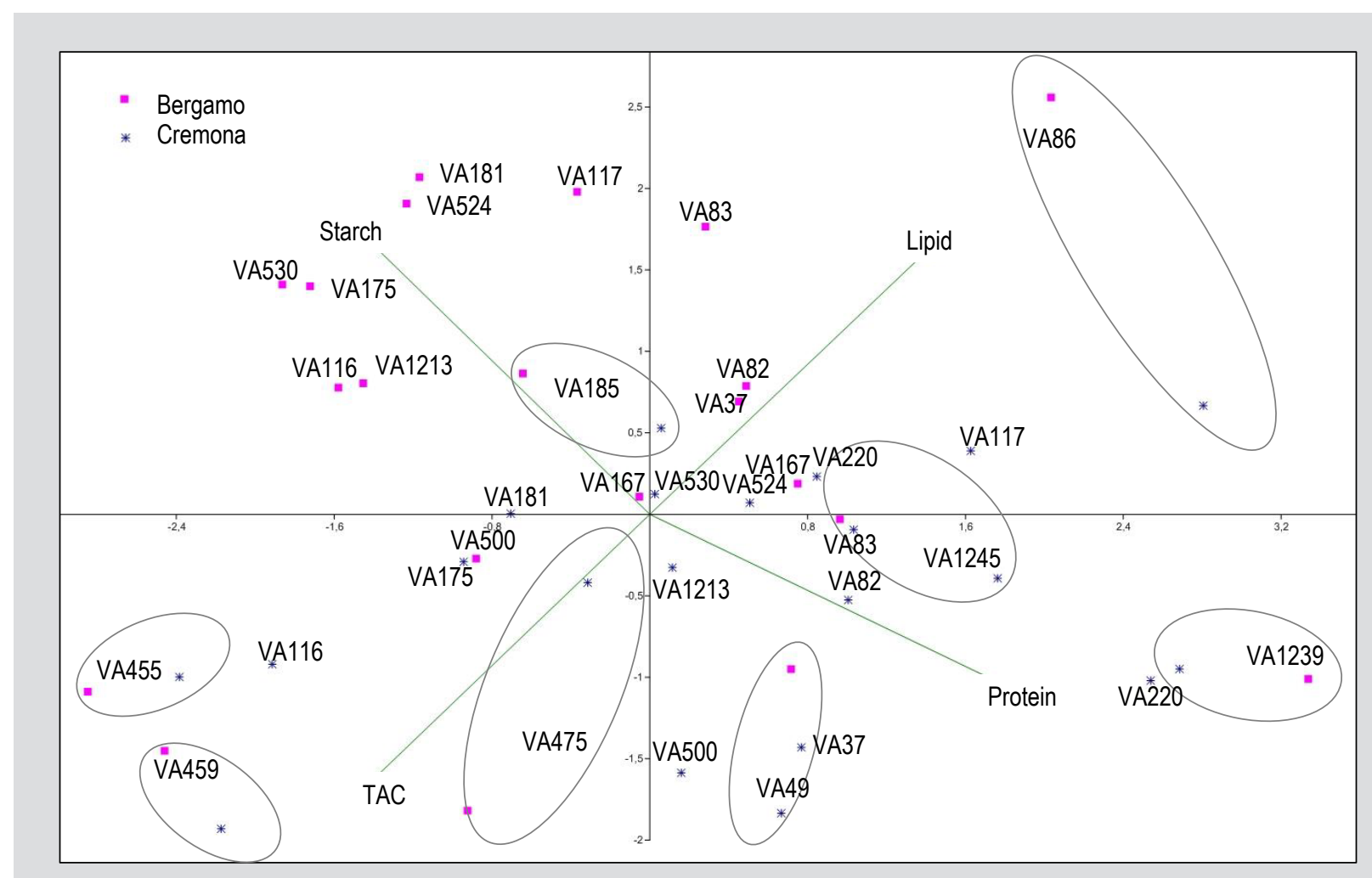

Figure 2. Principal components analysis of varieties grown in Bergamo and Cremona. Parameters considered: protein, lipid, starch, total antioxidant capacity (TAC). 
to enter and infect the ear. Moreover, an evaluation of noninoculated ears in order to detect environmental infection was performed.

NIK assay allows to evaluate the response of different genotypes to fungal artificial inoculation, observing the extension of the mycelium formed starting from the inoculum point. The average NIK of the twenty-one varieties inoculated either with $F$. verticillioides or with sterile water, in Bergamo and Cremona, was reported in Figure 3.

In general the ears contamination has been greater in Cremona than in Bergamo, both for water and Fusarium treatments. In fact treatments in Bergamo reached a mean value of 3.87 and 14.04 contaminated seeds while in Cremona, water and Fusarium treatments showed an average of 8.57 and 23.90 contaminated seeds. Moreover, ANOVA showed a significant difference between water and Fusarium treatments for both locations (Tukey test $P<0.05)$, underlining how the inoculation method can be used successful to discriminate genotypic responses to $F$. verticillioides. The average FBs content of ears inoculated with $F$. verticillioides, in comparison with the sterile water, in Bergamo and Cremona was illustrated in Figure 4.

FBs are present in all treatments, but in controls the mycotoxin amount was significantly lower than in inoculated materials, indicating that toxigenic strains used for experimentation produced a higher amount of mycotoxins in field trials than natural ones. Pearson correlation analysis showed that there is a close link between FBs content in genotypes with open and Fusarium treatments $(\mathrm{r}=0.51, P \leq 0.01)$. This finding is very interesting because, once the tolerance or susceptibility response to the pathogen is observed after artificial inoculation, an analogous response will be observed also with a natural field infestation.

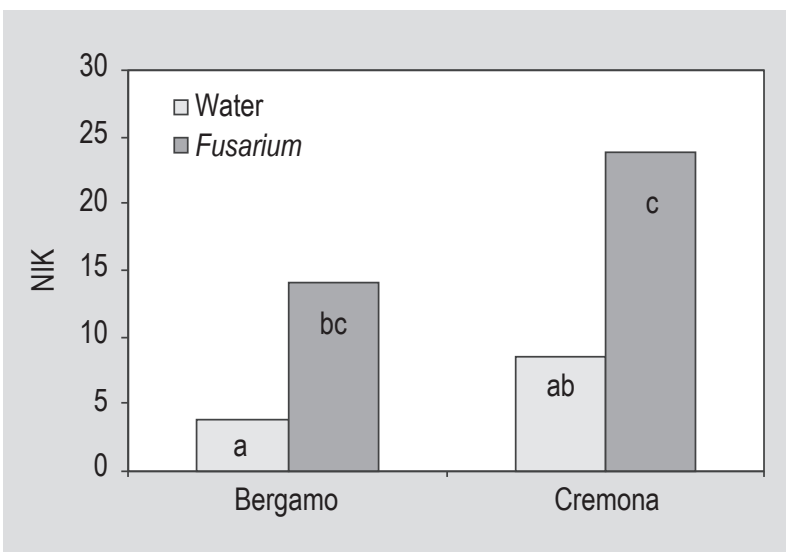

Figure 3. Average number of infected kernels (NIK) for 21 varieties inoculated with sterile water and with Fusarium verticillioides in Bergamo and Cremona.
The average FBs level for all treatments was higher in Cremona than in Bergamo. For both locations, average FB concentrations in varieties inoculated with fungal spore suspension (13,557 $\mu \mathrm{g} / \mathrm{kg}$ in Bergamo and 34,147 $\mu \mathrm{g} / \mathrm{kg}$ in Cremona), were significantly greater than in waterinoculated samples $(4,133 \mu \mathrm{g} / \mathrm{kg}$ in Bergamo and 6,135 $\mu \mathrm{g} / \mathrm{kg}$ in Cremona). A significant statistical difference was observed for both locations between treatments $(P<0.01$ T-student). The largest contamination in Cremona might partially be explained by the different soil texture of two environments. In Bergamo a greater level of precipitation was observed, during the whole crop cycle, compared to Cremona; but the medium-textured soil in Bergamo tends to make the water run quickly from the surface. On the contrary in Cremona the structure with a medium clay mixture tends to retain more water and humidity, favouring an increased growth of fungi and the relative presence of FBs (CAST, 2003).

In Table 3 NIK values and FB concentrations, determined at maturity in Bergamo and Cremona for twenty-one Fusarium-inoculated white maize varieties, are reported. The relative rankings of the varieties for both parameters are also included.

In detail, NIK ranged from 4.70 (VA1239) to 97.67 (VA49) in Cremona and from 6.89 (VA83) to 29.22 (VA475) in Bergamo. A classification of the varieties inoculated with Fusarium in three contamination classes according to disease severity was carried out: class I-low (NIK from 0 to 3 ) class II-medium (NIK from 3 to 18) and class III-high (NIK>18) disease severity. In Bergamo $86 \%$ of genotypes fell into the second class and only $14 \%$ exceeded the average of 18 contaminated kernels. On the other hand in Cremona $48 \%$ of the varieties observed showed more than 18 contaminated kernels (class III). Observing NIKrankings, VA167, VA1213 and VA 1249 had low NIK-score in both locations.

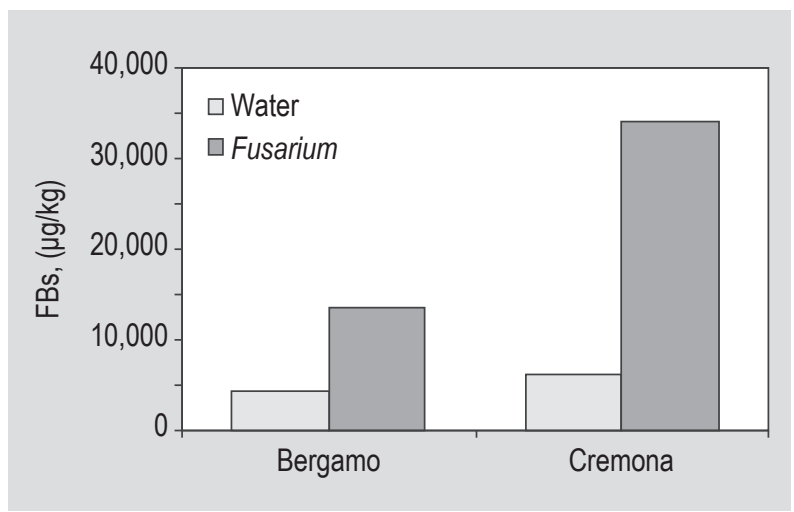

Figure 4. Average fumonisin concentrations(FBs) for 21 white maize varieties inoculated with sterile water or with Fusarium verticillioides in Bergamo and Cremona. 
Table 3. Mean number of infected kernels at the inoculation point (NIK) and fumonisin concentration (FBs, $\mu \mathrm{g} / \mathrm{kg}$ ) for the twentyone Italian white maize varieties evaluated after Fusarium verticillioides kernel inoculation in Cremona and Bergamo.

\begin{tabular}{|c|c|c|c|c|c|c|c|c|}
\hline \multirow[b]{2}{*}{ Variety } & \multicolumn{4}{|c|}{ Cremona } & \multicolumn{4}{|c|}{ Bergamo } \\
\hline & NIK & NIK rank & FBs & FBs rank & NIK & NIK rank & FBs & FBs rank \\
\hline VA 37 & 15.90 & 8 & 32,000 & 15 & 6.40 & 1 & 4,400 & 4 \\
\hline VA 49 & 97.67 & 21 & 105,900 & 20 & 23.80 & 19 & 15,800 & 15 \\
\hline VA 82 & 6.67 & 4 & 15,600 & 9 & 16.80 & 17 & 8,000 & 8 \\
\hline VA 83 & 17.56 & 11 & 13,800 & 8 & 6.89 & 2 & 11,500 & 10 \\
\hline VA 86 & 18.90 & 14 & 32,800 & 16 & 15.38 & 15 & 5,900 & 5 \\
\hline VA 116 & 18.10 & 12 & 6,900 & 1 & 11.78 & 9 & 7,000 & 7 \\
\hline VA 117 & 21.11 & 15 & 9,300 & 3 & 13.56 & 11 & 3,500 & 2 \\
\hline VA 167 & 6.30 & 3 & 13,200 & 6 & 9.67 & 6 & 23,000 & 19 \\
\hline VA 175 & 16.80 & 10 & 8,000 & 2 & 10.25 & 8 & 12,900 & 11 \\
\hline VA 181 & 37.20 & 18 & 58,600 & 18 & 12.22 & 10 & 14,500 & 14 \\
\hline VA 185 & 55.67 & 20 & 141,900 & 21 & 14.00 & 12 & 16,500 & 16 \\
\hline VA 220 & 18.80 & 13 & 25,000 & 12 & 8.78 & 4 & 14,300 & 12 \\
\hline VA 455 & 50.80 & 19 & 71,100 & 19 & 25.33 & 20 & 17,300 & 17 \\
\hline VA 459 & 33.20 & 17 & 20,500 & 11 & 8.40 & 3 & 4,300 & 3 \\
\hline VA 475 & 28.33 & 16 & 25,400 & 13 & 29.22 & 21 & 42,000 & 21 \\
\hline VA 500 & 7.57 & 5 & 51,600 & 17 & 14.57 & 13 & 14,400 & 13 \\
\hline VA 524 & 12.00 & 6 & 10,100 & 5 & 17.56 & 18 & 28,900 & 20 \\
\hline VA 530 & 16.00 & 9 & 20,400 & 10 & 16.33 & 16 & 21,500 & 18 \\
\hline VA 1213 & 6.00 & 2 & 9,700 & 4 & 10.00 & 7 & 6,700 & 6 \\
\hline VA 1239 & 4.70 & 1 & 13,500 & 7 & 9.00 & 5 & 9,100 & 9 \\
\hline VA 1245 & 12.70 & 7 & 31,800 & 14 & 15.00 & 14 & 3,200 & 1 \\
\hline Mean & 23.90 & & 34,148 & & 14.04 & & 13,557 & \\
\hline$S D$ & 21.90 & & 34,940 & & 6.10 & & 9,509 & \\
\hline
\end{tabular}

Moreover, FB concentrations $(\mu \mathrm{g} / \mathrm{kg})$ ranged from 3,200 (VA1239) to 42,000 (VA475) in Bergamo, and from 6,900 (VA116) to 141,900 (VA185) in Cremona. In both locations three varieties (VA116, VA117 and VA1213) showed low FBs amount (from 0 to $10,000 \mu \mathrm{g} / \mathrm{kg}$ ) and five varieties (VA83, VA167, VA220, VA524, VA530) showed medium FBs amounts (from 10,000 to $30,000 \mu \mathrm{g} / \mathrm{kg}$ ). Furthermore, the simple correlation coefficients between FB content and NIK were determined in both locations in samples inoculated with $F$. verticilliodes. FB concentrations were positively correlated with NIK both in Bergamo $(\mathrm{r}=0.60 ; P \leq 0.01)$ than in Cremona $(\mathrm{r}=0.79 ; P \leq 0.01)$. Furthermore, the correlation between NIK and FBs content shows that NIK is a simple and good parameter to identify resistant genotypes. This result is supported by analogous results obtained from Balconi et al. (2014) on Italian maize inbred lines.

\section{Conclusions and perspectives}

This study revealed the existence of a good variability among Italian traditional white maize varieties for nutritional qualities, agronomic performance and resistance to $F$. verticillioides. It is possible to highlight the presence of varieties with valuable quality traits in both location: VA86 for lipid content, VA1239 and VA1245 for protein content, VA185 for starch content. High TAC values were observed for VA455, VA459 and VA475 varieties which derive from the South of Italy. Moreover this research showed that Italian germplasm offers some interesting sources of resistance to Fusarium ear rot. In fact, three genotypes (VA117, VA1213 and VA1239) showed a low fumonisins accumulation, in both environments. These selected genotypes could be potentially suitable for breeding programs focused on: (1) the valorisation of the biodiversity of Italian maize white local varieties; and (2) improvement of the nutritional quality and safety of the grain. Moreover, the pasting properties of some genotypes will be analysed to verify their best end-use for the preparation of food products.

\section{References}

Bacchetti, T., Masciangelo, S., Micheletti, A. and Ferretti, G., 2013. Carotenoids, phenolic compounds and antioxidant capacity of five local Italian corn (Zea mays L.) kernels. Journal of Nutrition and Food Sciences 3: 6 
Balconi, C., Berardo, N., Locatelli, S., Lanzanova, C., Torri, A. and Redaelli, R., 2014. Evaluation of ear rot (Fusarium verticillioides) resistance and fumonisin accumulation in Italian maize inbred lines. Phytopatologia Mediterranea 53(1): 14-26.

Berardo, N., Lanzanova, C., Locatelli, S., Laganà, P., Verderio, A. and Motto, M., 2011. Levels of total fumonisins in maize samples from Italy during 2006-2008. Food Additives and Contaminants 4(2): 116-124.

Berardo, N., Mazzinelli, G., Valoti, P., Laganà, P. and Redaelli, R., 2009. Characterisation of maize germplasm for the chemical composition of the grain. Journal of Agricultural and Food Chemistry 57(6): 2378-2384.

Berardo, N., Pisacane, E., Valoti, P., Mariotti, M., D’Egidio, M.G. and Moscaritolo, S., 2006. Development of innovative maize based products as functional foods. Tecnica Molitoria International 57(5A): 103-108.

Bitocchi, E., Nanni, L., Rossi, M., Rau, D., Bellucci, E., Giardini, A., Buonamici, A., Vendramin, G.G. and Papa, R., 2009. Introgression from modern hybrid varieties into landrace populations of maize (Zea mays ssp. Mays L.) in central Italy. Molecular Ecology 18: 603-621.

Brandolini, A. and Brandolini, A., 2001. Classification of Italian maize (Zea mays L.) germplasm. Plant Genetic Resources Newsletter 126: 1-11.

Brandolini, A. and Brandolini, A., 2009. Maize introduction, evolution and diffusion in Italy. Maydica 54: 233-242.

Brewer, M.S., 2011. Natural antioxidants: sources, compounds, mechanisms of action, and potential applications. Comprehensive Reviews in Food Science and Food Safety 10: 221-247.

Camardo Leggieri, M., Bertuzzi, T., Pietri, A. and Battilani, P., 2015. Mycotoxin occurrence in maize produced in Northern Italy over the years 2009-2011: focus on the role of crop related factors. Phytopathologia Mediterranea 54(2): 212-221.

Cao, A., Santiago, R., Ramos, A.J., Souto, X.C., Aguin, O., Malvar, R.A. and Burtòn, A., 2014. Critical environmental and genotypic factors for Fusarium verticillioides infection, fungal growth and fumonisin contamination in maize grown in northwestern Spain. International Journal of Food Microbiology 177: 63-71.

Council for Agricultural Science and Technology (CAST), 2003. Mycotoxins: risks in plant, animal, and human systems. Task Force report 139. CAST, Ames, IA, USA.

Castegnaro, M. and McGregor, D., 1998. Carcinogenic risk assessment of mycotoxins. Revue de Médecin Vétérinaire 419: 671-678.

Community Plant Variety Office (CPVO), 2010. CPVO-TP/002/3. Protocol for distinctness, uniformity and stability test (Zea mays L.). Available at: http://cpvo.europa.eu/sites/default/files/documents/ TP/agricoles/TP_002-3_ZEA_MAYS.pdf.

European Commission (EC), 2006. Regulation No 1881/2006 of 19 December 2006 setting maximum levels for certain contaminants in foodstuffs. EC, Brussels, Belgium.

European Commission (EC), 2007. Regulation No 1126/2007 of 28 September 2007 amending Regulation (EC) No 1881/2006 setting maximum levels for certain contaminants in foodstuffs as regards Fusarium toxins in maize and maize products. EC, Brussels, Belgium.
Guelpa, A., Bevilacqua, M., Marini, F., O’Kennedy, K., Geladi, P. and Manley, M., 2015. Application of Rapid Visco Analyser (RVA) viscograms and chemometrics for maize hardness characterization. Food Chemistry 173: 1220-1227.

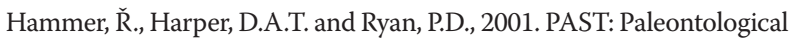
statistics software package for education and data analysis. Palaeontologia Electronica 4(1): 9.

Hartings, H., Berardo, N., Mazzinelli, G., Valoti, P., Verderio, A. and Motto, M., 2008. Assessment of genetic diversity and relationships among maize (Zea mays L.) Italian landraces by morphological traits and AFLP profiling. Theoretical and Applied in Genetics 111: 831-842.

Lanzanova, C., Alfieri, M., Locatelli, S., Mascheroni, S., Facchinetti, F., Valoti, P., Balconi, C. and Redaelli, R., 2016. Quality and safety of Italian white maize varieties. Tecnica Molitoria International 16(17/A): 52-61.

Lonzano-Alejo, N., Vazquez Carrillo, G., Pixley, K. and Palacios-Rojas, N., 2007. Physical properties and carotenoid content of maize kernels and its nixtamalized snacks. Innovative Food Science and Emerging Technologies 8(3): 385-389.

Mesterházy, A., Lemmens M. and Reid, L.M., 2012. Breeding for resistance to ear rots caused by Fusarium spp. in maize - a review. Plant Breeding 131: 1-19.

Miedaner, T., Bolduan, C. and Melchinger, A.E., 2010. Aggressiveness and mycotoxin production of eight isolates each of Fusarium graminearum and Fusarium verticillioides for ear rot on susceptible and resistant early maize inbred lines. European Journal of Plant Pathology 127: 113-123.

Miller, J.D., 2001. Factors that affect the occurrence of fumonisins. Environmental Health Perspectives 109: 321-324.

Nuss, E.T. and Tanumihardjo, S.A., 2010. Maize: a paramount staple crop in the context of global nutrition. Comprehensive Reviews in Food Science and Food Safety 4(9): 417-436.

Pereira, P., Ibañez, S.G., Agostini, E. and Etcheverry, M., 2011. Effects of maize inoculation with Fusarium verticillioides and with two bacterial biocontrol agents on seedlings growth and antioxidative enzymatic activities. Applied Soil Ecology 51: 52-59.

Pietri, A., Battilani, P., Gualla, A. and Bertuzzi, T., 2012. Mycotoxin levels in maize produced in northern Italy in 2008 as influenced by growing location and FAO class of hybrid. World Mycotoxin Journal 5: 409-418.

Redaelli, R., Alfieri, M. and Cabassi, G., 2016. Development of a NIRS calibration for total antioxidant capacity in maize germplasm. Talanta 154: 164-168.

Reid, L.M., Hamilton, R.I. and Mather, D.E., 1996. Screening maize for resistance to Gibberella ear rot. Technical Bulletin 1996-5E, Research Branch, Agriculture and Agri-Food, St. John's, NL, Canada.

Rooney, L.W. and Serna Saldívar, S.O., 2003. Food use of whole corn and dry-milled fractions. In: White, P.J. and Johnson, L.A. (eds.) Corn: chemistry and technology, $2^{\text {nd }}$ edition. AACC, St. Paul, MN, USA, pp. 495-535.

Serpen, A., Capuano, E., Fogliano, V. and Gökmen, V., 2007. A new procedure to measure the antioxidant activity of insoluble food components. Journal of Agricultural and Food Chemistry 55: 7676-7681. 
Tafuri, A., Alfieri, M. and Redaelli, R., 2014. Determination of soluble phenolics content in Italian maize varieties and lines. Tecnica Molitoria International 65(15/A): 60-69.

Torri, A., Lanzanova, C., Locatelli, S., Valoti, P. and Balconi, C., 2015. Screening of local Italian maize varieties for resistance to Fusarium verticillioides. Maydica 60(1): 1-8.
Zeppa, G., Bertolino, M. and Rolle, L., 2011. Quantitative descriptive analysis of Italian polenta produced with different corn cultivars. Journal Science and Food Agriculture 92: 412-417. 
